\title{
Kontribusi aktifitas fisik, kebugaran jasmani terhadap hasil belajar pendidikan jasmani
}

\section{Contribution of physical activity, physical fitness to learning outcomes of physical education}

\author{
Pulung Riyanto ${ }^{1}$ \\ ${ }^{1}$ Program studi PJKR, Universitas Musamsus, Indonesia
}

\begin{abstract}
Abstrak
Hasil belajar siswa tidak hanya ditentukan oleh kemampuan intelegensi siswa saja, aktifitas fisik dan kebuagaran jasmani siswa juga berpengaruh terhadap hasil belajar siswa. Di zaman modern ini banyak sekali penelitian yang mengkaji tentang pentingnya aktifitas fisk dan kebuagaran jasmani terhadap hasil belajar dalam Pendidikan jasmani. Penelitian menggunakan penelitian korelasi. Instruman yang digunakan dalam mengukur aktifitas fisik dengan menggunakan International Physical Activity Questionnaire (IPAQ), sedangkan untuk mengukur kebugaran jasmani menggunakan Tes Kebugaran Jasmani Indonesia (TKJI). Hasil belajar siswa di pengaruhi oleh kebuagaran jasmani dan aktifitas fisik siswa. Pengaruh yang diberikan aktifitas fisik tidak hanya bersifat sementara akan tetapi bersifat jangka Panjang. Guna mempertahankan hasil belajar dalam Pendidikan Jasmani maka seorang guru harus bisa memberikan aktifitas fisik yang terprogram dan menjaga kebugaran jasmani siswa.
\end{abstract}

Kata kunci: Aktivitas fisik, Kebugaran jasmani, hasil belajar.

\begin{abstract}
Student learning outcomes are not only determined by the ability of student intelligence, physical activity and physical disability of students also affect student learning outcomes. In this modern era a lot of research that examines the importance of physical activity and physical disruption of learning outcomes in physical education. Research using correlation research. The instruments used to measure physical activity are using the International Physical Activity Questionnaire (IPAQ), whereas to measure physical fitness use the Indonesian Physical Fitness Test (TKJI). Student learning outcomes are influenced by physical disabilities and physical activity of students. The effects of physical activity are not only temporary but are long-term. To maintain learning outcomes in Physical Education, a teacher must be able to provide programmed physical activity and maintain students' physical fitness.
\end{abstract}

Keywords: Physical Activity; Physical Fitness; Learning Outcomes.

\section{PENDAHULUAN}

Masa Sekolah Menengah Pertama merupakan masa promosi dalam pemahaman dalam pentingnya atktifitas fisik dan kebugaran jasmani. Promosi ini diharapkan dapat melekat pada anak, dan anak menyadari pentingnya aktifitas fisik dan partispasi dalam olahraga (Martin, 2010). Sekolah juga merupakan lembaga yang berperan dalam membiasakan aktifitas fisik bagi anak (Arrigon, 2019). 
Aktifitas fisik ini diharapkan dapat mencegah gejala psikologis dan untuk melindungi kesehatan mental di kalangan siswa (Tanır \& Özmaden, 2018). Pentingya melakukan aktifitas fisik merupakan salah satu hal yang penting, mengingat dampak yang ditimbulkan jika tidak melakukan aktifitas fisik diantaranya darah tinggi, obesitas dan lain lain. Ketidakaktifan fisik telah diidentifikasi sebagai faktor risiko utama keempat untuk kematian global (6\% dari kematian secara global). Ini mengikuti tekanan darah tinggi (13\%), penggunaan tembakau (9\%) dan glukosa darah tinggi (6\%). Kegemukan dan obesitas bertanggung jawab atas 5\% dari kematian global (WHO, 2010). Aktifitas fisik jika tidak dijadwalkan dengan baik di sekolah akan mengakibatkan dengan mudahnya terjangkit berbagai macam penyakit (Gordon Bietz, 2012).

Untuk mencegah penyakit tersebut tanamkan dalam diri kita bahwa aktifitas fisik dianggap sebagai pil (Prevention, 2017). Aktivitas fisik sebagai instrumen yang efektif untuk membangun psikologis kesejahteraan. Kaitannya dengan peningkatan prestasi akademik siswa maka dengan melakukan aktifitas fisik akan meningkatkan kemapuan kognisi, memori dan lain lain (Kayani et al., 2018). Hal lain juga mengenai pentingnya aktifitas fisik adalah menjadikan sekolah sebagai tempat yang nyaman untuk belajar (Piercy et al., 2018). Dua puluh menit aktivitas fisik harian sangat penting tidak hanya untuk meningkatkan prestasi siswa tetapi juga untuk membuat sekolah yang didanai publik menjadi tempat yang lebih sehat untuk belajar (Ahamed et al., 2007). Selain meningkatkan dalam kemampuan akademisi aktifitas fisik juga dapat meningkatkan kualitas hidup seseorang (Tsafou, De Ridder, van Ee, \& Lacroix, 2016).

Pemahaman yang kurang dari siswa mengenai pentingnya kebugaran jasmani di dalam kehidupan akan mengurangi minat siswa dalam mengikuti mata pelajaran olahraga di sekolah. Di negara negara berkembang tidak menutup kemungkinan rendahnya partisipasi siswa dalam mengikuti mata pelajaran olahraga di sekolah. Menurut Shape of the Nation Report 2006, sebuah studi bersama baru-baru ini yang dilakukan oleh Asosiasi Nasional untuk Olahraga dan Pendidikan Jasmani (NASPE) dan American Heart Association (AHA), hanya 56 persen siswa sekolah menengah yang berpartisipasi dalam pendidikan jasmani, dan persentase sekolah yang membutuhkan pendidikan jasmani di setiap kelas secara bertahap turun dari tingkat kelas dari 50 persen di kelas satu hingga kelas lima menjadi 5 persen di kelas 12. Selanjutnya, siswa yang menghadiri kelas pendidikan jasmani harian menurun dari 42 persen pada tahun 1991 menjadi 28 persen pada tahun 2003, dan hanya 8 persen sekolah dasar, 6,4 persen sekolah menengah pertama / SMP, dan 5,8 persen sekolah menengah atas menyediakan pendidikan jasmani harian di bawah pedoman yang direkomendasikan (Lynn, 2007). 
Terdapat beberapa pengertian dari beberapa ahli mengenai aktivitas fisik di antaranya Aktivitas fisik adalah komponen dari proses kompleks yang melibatkan pengembangan, pembelajaran dan asimilasi keterampilan, nilai-nilai, norma, persepsi diri, identitas dan peran yang disediakan oleh berbagai variabel lingkungan keluarga dan keterlibatan sosial, seperti kelompok sosio-demografi, profesi, pendidikan dan area tempat tinggal, yang mungkin menjadi faktor potensial yang mempengaruhi aktivitas fisik anak-anak dan remaja di waktu luang mereka (Batista, Cubo, Honório, \& Martins, 2016). Dimana aktivitas fisik adalah komponen dari proses kompleks yang melibatkan pengembangan, pembelajaran dan asimilasi keterampilan, nilai-nilai, norma, persepsi diri, identitas (Gråstén, 2014).

Pengertian lain mengenai aktivitas fisik adalah sarana mendasar untuk meningkatkan kesehatan fisik dan mental. Namun, bagi banyak orang, ia telah dihapus dari kehidupan sehari-hari, dengan efek dramatis bagi kesehatan dan kesejahteraan (Cavill, Kahlmeier, \& Racioppi, 2012). Dimana aktivitas adalah sarana mendasar untuk meningkatkan kesehatan fisik dan mental. Namun banyak orang telah menghilangkan semua itu dari kehidupan sehari-hari, dengan dampak yang luar biasa bagi kesehatan dan kesejahteraan. Faktor penunjang di antaranya seperti sistem kardiovascular, skelet, muscle dan nervorum. Proeses yang memerlukan pengeluaran energi yang melibatkan gerakan tubuh yang dihasilkan otot merupakan sebuah aktivitas fisik. Salah satu penyebab kematian yang sangat global menurut WHO di antaranya adalah penyakit kronis, hal ini merupakan factor resiko independent dimana meruapakan kurangnya aktivitas fisik (Meeting \& Organization, 2010). Gerakan yang dilakukan dengan berulang-ulang dengan tujuan untuk meningkatkan kebuagaran jasmani dimana didalamnya merupakan aktivitas fisik yang terencana dan terstruktur (Khomarun, 2013). Berdasarkan pendapat para ahli di atas aktivitas fisik ialah gerakan tubuh oleh otot tubuh dan sistem penunjangnya yang memerlukan pengeluaran energi. Aktivitas fisik adalah setiap gerakan tubuh yang membutuhkan energi untuk mengerjakannya.

Kebugaran fisik adalah keadaan adaptif yang dapat didefinisikan sebagai seperangkat atribut yang dimiliki atau dicapai orang yang berkaitan dengan kemampuan untuk melakukan aktivitas fisik. (Nwimo \& Orji, 2015). Kebugaran fisik, yang berkaitan dengan konsep Total Force Fitness (TFF), didefinisikan sebagai satu set atribut yang berhubungan dengan kesehatan atau kinerja yang berkaitan dengan aktivitas dan kondisi tubuh. (Robson, 2014). Aktivitas fisik dalam istilah fisiologis mengacu pada "... gerakan tubuh yang dihasilkan oleh otot rangka dan menghasilkan pengeluaran energi (Monyeki \& Kemper, 2007). Kebugaran fisik adalah seperangkat atribut yang dimiliki atau dicapai 
orang yang berkaitan dengan kemampuan mereka untuk melakukan aktivitas fisik (StuartCassel, 2015). Kebugaran fisik didefinisikan sebagai kemampuan untuk melakukan tugas sehari-hari dengan semangat dan kewaspadaan tanpa kelelahan yang berlebihan dengan energi yang cukup untuk menikmati kegiatan waktu luang, untuk memenuhi situasi yang tidak biasa dan keadaan darurat yang tidak terduga. (Akre \& Bhimani, 2015).

\section{METODE}

Metode yang digunakan dalam penelitian ini adalah metode deskriptif. Populasi yang digunakan adalah siswa kelas VII SMP Negeri 1 Merauke. Sampel adalah siswa kelas VII A SMP Negeri 1 Merauke dengan pengambilan sampel dilakukan secara cluster random sampling. Penelitian ini merupakan penelitian korelasi, karena di dalam penelitian ini bertujuan untuk menemukan ada tidaknya hubungan antara aktifitas fisik dan kebuagaran jasmani terhadap hasil belajar Pendidikan Jasmani. Instruman yang digunakan dalam mengukur aktifitas fisik dengan menggunakan International Physical Activity Questionnaire (IPAQ), sedangkan untuk mengukur kebugaran jasmani menggunakan Tes Kebugaran Jasmani Indonesia (TKJI).

\section{HASIL DAN PEMBAHASAN}

\section{Hasil}

Berdasarkan hasil penghitungan di dapat hasil penghitungan sebagai berikut:

\section{Tabel 1}

Hasil perhitungan korelasi

\begin{tabular}{lllll}
\hline & & Aktifitas Fisik & Kebugaran Jasmani & Hasil Belajar \\
\hline \multirow{2}{*}{ Aktifitas Fisik } & Pearson Correlation & 1 & .257 & $.608^{* *}$ \\
\cline { 2 - 5 } & Sig. (2-tailed) & & .130 & .000 \\
\cline { 2 - 5 } & $\mathrm{N}$ & 36 & 36 & 36 \\
\hline \multirow{2}{*}{ Kebugaran Jasmani } & Pearson Correlation & .257 & 1 & $.617^{* *}$ \\
\cline { 2 - 5 } & Sig. (2-tailed) & .130 & 36 & .000 \\
\cline { 2 - 5 } & $\mathrm{N}$ & 36 & $.617^{* *}$ & 36 \\
\hline Hasil Belajar & Pearson Correlation & $.608^{* *}$ & .000 & 1 \\
\cline { 2 - 5 } & Sig. (2-tailed) & .000 & 36 & 36 \\
\cline { 2 - 5 } & $\mathrm{N}$ & 36 & & 36 \\
\hline
\end{tabular}

Berdasarkan tabel di atas hubungan antara aktifitas fisik dan kebugaran jasmani menunjukan nilai signifikansi 0,000 . Hal ini menunjukan bahwa terdapat korelasi yang signifikan dari aktifikas fisik dan kebugaran jasmani terhdap hasil belajar Pendidikan jasmani. Adapun besarnya sumbangan yang diberikan oleh aktifitas fisik dan kebugaran 
jasmani terhdap hasil belajar Pendidikan jasmani di SMP Negeri Merauke dapat dilihat pada tabel berikut ini:

\section{Tabel 2}

\section{Kontribusi aktivitas fisik dan kebugaran jasmani}

\begin{tabular}{r|lr|r}
\hline & $\begin{array}{l}\text { Cronbach's Alpha } \\
\text { Based on } \\
\text { Standardized }\end{array}$ & \\
Cronbach's Alpha & $\begin{array}{l}\text { Items } \\
\text { I442 }\end{array}$ & N of Items & \\
\hline
\end{tabular}

Besarnya sumbangan yang diberikan oleh aktifikas fisik dan kebugaran jasmani terhdap hasil belajar Pendidikan jasmani sebesar $74 \%$. Kebugaran jasmani yang dimiliki oleh siswa akan memberikan dampak yang positif dalam kehidupannya. Selain berdampak terhadap kesehatan, kebugaran jasmani juga akan berdampak pada peningkatan kemampuan akademik. Dalam perkembangan di pendidikan jasmani, pembelajaran yang dikemas oleh seorang guru akan memberikan dampak yang positif terhadap hasil belajar. Di sekolah dalam proses pembelajaran, kebanyakan guru masih mengadopsi model pembelajaran yang tidak sesusi. Kegiatan pembelajaran dilakukan dengan monoton, hal ini bisa diartikan sebagai model yang konvensional (Riyanto, 2019). Pendapat ini didukung oleh badan penelitian dunia dimana kebugaran jasmani memiliki pengaruh terhadap hasil akadamik dan koognitif siswa. (Kyan, Takakura, \& Miyagi, 2018).

Pemberian kontribusi dari aktifitas fisik dan kebugaran jasmani diharapkan membuka pikiran anak anak mengenani pentingnya aktifitas fisik dan kebuagaran jasmani, diharapkan akan memberikan manfaat dalam peningkatan kemampuan akademik siswa dan konsentasinya (Chomitz et al., 2009). Perubahan pola pikir ini diharapkana akan memberikan pemahaman yang baik dimana kebugaran jasmani yang dimiliki seseorang akan meningkat dengan melakukan aktifitas fisik. Dimana tidak ada lagi pemahan yang terbalik bahwa olahraga membuat badan menjadi pegal atau susah dilakukan. (Ortega, Ruiz, Castillo, \& Sjöström, 2008).

Aktivitas fisik dan olahraga memiliki ruang lingkup intervensi dalam motor kognitif, sosial dan fisik, sebagai sarana yang sangat baik untuk perkembangan motorik anak, memberikan kontribusi untuk pendidikan dan pelatihan yang sama, di mana ia mempromosikan kegiatan yang sehat dalam lingkungan yang menyenangkan, dipromosikan. kesehatan fisik dan psikologis 
(Batista et al., 2016). Penelitian aktivitas fisik (PA) dalam domain pembelajaran fisik pengaturan sekolah dasar telah berpengaruh dalam menggerakkan praktik pendidikan jasmani (PE) menuju hasil terkait kesehatan (Miller et al., 2016). Pendidikan jasmani yang dikembangkan di sekolah harus menjadi perhatian khusus supaya memberikan kontribusi dalam peningkatan prestasi akademik siswa. Banyak fakta dilapangan yang memberikan contoh mengenai dampak atifitas fisik terhadap kemampuan akademik siswa, hal ini memberikan asumsi bahwa aktifitas fisik berkorelasi dalam peningkatan hasil belajar siswa (Wadsworth, Rudisill, Hastie, Boyd, \& Rodríguez-Hernández, 2014). Fakta mengenai aktifitas fisik dilapangan adalah dengan dikemas dalam pendidikan jasmani, dengan pendidikan jasmani ini akan memberikan dampak terhadap peningkatan akademik siswa. (Sallis et al., 2012).

Aktifiktas fisik harus diberikan kepada siswa dalam pembelajaran dengan menekankan pada adanya interaksi anatara siswa dan guru, sehingga hal ini akan meningkatkan pada pencapaian hasil belajar yang maksimal. Interaksi ini diharapkan akan memberikan perubahan paradigma bahawa dalam pemberikan aktifitas fisik tidak hanya terfokus pada satu titik saja, akan tertapi harus adanya interaksi (Gao, Lee, Xiang, \& Kosma, 2011). Aktifitas fisik tidak hanya dilakukan di luar ruangan, bisa juga dilakukan di dalam ruangan. Walapun dilakukan di dalam ruangan aktifitas fisik juga memberikan dampak yang positif dalam meningkatkan hasil belajar siswa. (Rasberry et al., 2011).

Guna meningkatkan hasil belajar yang maksimal maka di indonesia khususnya di merauke maka perlu adanya mempromosikan aktifitas fisik di sekolah. Aktifitas fisik ini harus terintegrasi dalam mata pelajaran pendidikan jasmani olahraga dan kesehatan supaya bisa meningkatkan pengetahuan siswa. Di negara-negara Nordik, kurikulum PE saat ini kurang fokus pada pencapaian fisik dan lebih fokus pada bagaimana mempromosikan pola aktivitas fisik di masa dewasa. Ini dilakukan dengan memberikan teladan, pengetahuan dan keterampilan dalam pendidikan jasmani (Bertills, Granlund, Dahlström, \& Augustine, 2018). Hal lain yang bisa digunakan adalah menggabungkan pendidikan jasmani dengan aktifitas yang terstruktur akan meningkatkan kemampuan akademik siswa. (Mullender-Wijnsma et al., 2015).

Manfaat yang diberikan dari aktifitas fisik di sekolah tidak hanya pada waktu melakukan aktifitas fisik saja. Manfaat yang diberikan bersifat jangka panjang, manfaat dalam hal ini berkaitan dengan kemampuan akademik siswa. Siswa yang terlibat dalam 
aktifitas fisik akan lebih mudah dalam mengerjakan tugas yang diberikan guru dan bermanfaat dalam peningkatan akademik siswa. (Castelli, Glowacki, Barcelona, Calvert, \& Hwang, 2015). Guru juga harus bisa memberikan konsep masa depan kepada siswa supaya siswa memiliki rasa yang kuat dalam meningkatkan aktifitas fisik dan kebuagaran jasmani siswa. Konsep diri ini diharapkan dapat meningkatkan perasaan saat ini dan masa depan (Pulung \& Betaubun, 2019).

\section{KESIMPULAN}

Hasil belajar merupakan salah satu output yang dilihat dalam melihat hasil pembelajaran dalam pendidikan jasmani olahraga dan kesehatan di sekolah. Aktifitas fisik yang diiberikan kepada siswa yang didesain dengan terstruktur akan memberikan dampak terhadap peningkatan hasil belajar siswa. Hasil belajar siswa juga dipengaruhi oleh kebuagaran jasmani siswa. Perlu adanya sinkronisasi antara aktifitas fisik dengan pembelajaran Pendidikan jasmani di sekolah, hal ini akan berdampak pada peningkatan hasil belajar siswa. Sinkronisasi yang dilakukan tidak hanya berkaitan dengan jenis olahraga yang diberikan, akan tetapi berkaitan dengan kualitas dan jenis aktifitas fisik. Pembelajaran yang diberikan jangan hanya diberikan dengan pesan yang kosong tanpa adanya manfaat yag tepat. Salah satu hal yang tidak bisa dilupakan adalah berkaitan dengan kebugaran jasmani siswa yang harus diperhatikan dalam setiap jenjang pendidikan.

\section{DAFTAR PUSTAKA}

Ahamed, Y., MacDonald, H., Reed, K., Naylor, P.-J., Liu-Ambrose, T., \& Mckay, H. (2007). School-based physical activity does not compromise children's academic performance. Medicine \& Science in Sports \& Exercise, 39(2), 371-376.

Akre, A., \& Bhimani, N. (2015). Co-relation between physical fitness index (PFI) and body mass index in asymptomatic college girls. Journal of Exercise Science and Physiotherapy, 11(2), 129.

Arrigon, D. (2019). What works in schools and colleges to increase physical activity? A resource for head teachers, college principals, staff working in education settings, school nurses, directors of public health, county sports partnerships and wider partners.

Batista, M., Cubo, D. S., Honório, S., \& Martins, J. (2016). The practice of physical activity related to self-esteem and academical performance in students of basic education. Journal of Human Sport and Exercise, 11(2), 297-310.

Bertills, K., Granlund, M., Dahlström, Ö., \& Augustine, L. (2018). Relationships between physical education (PE) teaching and student self-efficacy, aptitude to participate in PE and functional skills: with a special focus on students with disabilities. Physical Education and Sport Pedagogy, 23(4), 387-401. 
Castelli, D. M., Glowacki, E., Barcelona, J. M., Calvert, H. G., \& Hwang, J. (2015). Active education: Growing evidence on physical activity and academic performance. Active Living Research, 1, 1-5.

Cavill, N., Kahlmeier, S., \& Racioppi, F. (2012). Physical activity and health in Europe: evidence for action. World Health Organization.

Chomitz, V. R., Slining, M. M., McGowan, R. J., Mitchell, S. E., Dawson, G. F., \& Hacker, K. A. (2009). Is there a relationship between physical fitness and academic achievement? Positive results from public school children in the northeastern United States. Journal of School Health, 79(1), 30-37.

Fedewa, A. L., \& Ahn, S. (2011). The effects of physical activity and physical fitness on children's achievement and cognitive outcomes: a meta-analysis. Research Quarterly for Exercise and Sport, 82(3), 521-535.

Gao, Z., Lee, A. M., Xiang, P., \& Kosma, M. (2011). Effect of Learning Activity on Students' Motivation, Physical Activity Levels and Effort/Persistence. ICHPER-SD Journal of Research, 6(1), 27-33.

Gordon Bietz. (2012). Living a Balance Life Physical Activity quality enhancement plan revised. Southern Adventist University.

Gråstén, A. (2014). Students' physical activity, physical education enjoyment, and motivational determinants through a three-year school-initiated program. Studies in Sport, Physical Education and Health, (205).

Kayani, S., Kiyani, T., Wang, J., Zagalaz Sánchez, M., Kayani, S., \& Qurban, H. (2018). Physical Activity and Academic Performance: The Mediating Effect of Self-Esteem and Depression. Sustainability, 10(10), 3633.

Khomarun, W. (2013). ES, \& Nugroho, MA (2013). Pengaruh Aktivitas Fisik Jalan Pagi Terhadap Penurunan Tekanan Darah Pada Lansia Dengan Hipertensi Stadium 1 Di Posyandu lansia Desa Makam Haji. Jurnal Terpadu Ilmu Kesehatan, 2(2), 144-149.

Kyan, A., Takakura, M., \& Miyagi, M. (2018). Does physical fitness affect academic achievement among Japanese adolescents? A hybrid approach for decomposing within-person and between-persons effects. International Journal of Environmental Research and Public Health, 15(9), 1901.

Lynn, S. (2007). The case for daily physical education. Journal of Physical Education, Recreation \& Dance, 78(5), 18-21.

Martin, K. (2010). Brain boost: Sport and physical activity enhance children's learning. The University of Western Australia: Crawley, WA, Australia.

Meeting, W. H. O. E. C. on the C. of the L., \& Organization, W. H. (2010). Control of the Leishmaniases: Report of a Meeting of the WHO Expert Committee on the Control of Leishmaniases, Geneva, 22-26 March 2010 (Vol. 949). World Health Organization.

Miller, A., Christensen, E., Eather, N., Gray, S., Sproule, J., Keay, J., \& Lubans, D. 
(2016). Can physical education and physical activity outcomes be developed simultaneously using a game-centered approach? European Physical Education Review, 22(1), 113-133.

Monyeki, M. A., \& Kemper, H. C. G. (2007). Is there a Positive Relationship between Physical fitness and Physical Activity in children?-A Brief Review. Journal of Exercise Science and Physiotherapy, 3(1), 12-16.

Mullender-Wijnsma, M. J., Hartman, E., de Greeff, J. W., Bosker, R. J., Doolaard, S., \& Visscher, C. (2015). Improving academic performance of school-age children by physical activity in the classroom: 1-year program evaluation. Journal of School Health, 85(6), 365-371.

Nwimo, I. O., \& Orji, S. A. (2015). Physical fitness among school children: Review of empirical studies and implications for physical and health education. J. Tourism Hosp. Sports, 10, 9-15.

Ortega, F. B., Ruiz, J. R., Castillo, M. J., \& Sjöström, M. (2008). Physical fitness in childhood and adolescence: a powerful marker of health. International Journal of Obesity, 32(1), 1-11.

Piercy, K. L., Troiano, R. P., Ballard, R. M., Carlson, S. A., Fulton, J. E., Galuska, D. A., ... Olson, R. D. (2018). The physical activity guidelines for Americans. Jama, 320(19), 2020-2028.

Prevention, C. for D. C. and. (2017). Physical activity builds a healthy and strong America.

Pulung, R., \& Betaubun, P. (2019). Efect ofStudent Learning Model on Emotional Intelligence. Nternational Journal of Management(IJM), 10(6), 54-60.

Rasberry, C. N., Lee, S. M., Robin, L., Laris, B. A., Russell, L. A., Coyle, K. K., \& Nihiser, A. J. (2011). The association between school-based physical activity, including physical education, and academic performance: a systematic review of the literature. Preventive Medicine, 52, S10-S20.

Riyanto, P. (2019). Pengaruh Model Pembelajaran Jigsaw Terhadap Peningkatan Kemampuan Drible Bola Basket. Musamus Journal of Physical Education and Sport (MJPES), 2(01), 59-67.

Robson, S. (2014). Physical Fitness and Resilience: A Review of Relevant Constructs, Measures, and Links to Well-Being. Rand Health Quarterly, 3(4).

Sallis, J. F., McKenzie, T. L., Beets, M. W., Beighle, A., Erwin, H., \& Lee, S. (2012). Physical education's role in public health: Steps forward and backward over 20 years and HOPE for the future. Research Quarterly for Exercise and Sport, 83(2), $125-135$.

Stead, R., \& Neville, M. (2010). The impact of physical education and sport on education outcomes: a review of literature. Loughborough: Institute of Youth Sport.

Stuart-Cassel, V. (2015). School-Based Physical Fitness and the Link to Student Academic Outcomes and Improved School Climate. Retrieved from: The National 
Center on Safe and Supportive Learning ....

Tanır, H., \& Özmaden, M. (2018). The Importance of Physical Activity in the Protection of the Mental Health of Students of Faculty of Sport Sciences. Journal of Education and Training Studies, 6(10), 92-97.

Tsafou, K.-E., De Ridder, D. T. D., van Ee, R., \& Lacroix, J. P. W. (2016). Mindfulness and satisfaction in physical activity: A cross-sectional study in the Dutch population. Journal of Health Psychology, 21(9), 1817-1827.

Wadsworth, D. D., Rudisill, M. E., Hastie, P. A., Boyd, K. L., \& Rodríguez-Hernández, M. (2014). Preschoolers' physical activity and time on task during a mastery motivational climate and free play. MHSalud, 11(1), 26-34.

WHO. (2010). Global recommendations on physical activity for health. World Health Organization. 